\title{
A Influência Territorial da Agroindústria Catarinense: a fusão entre a Perdigão e Sadia e as transformações na cidade de Videira-SC
}

\author{
The Territorial Influence of de Catarinian Agroindustria: the merger between Perdigão and \\ Sadia and the transformations in the city of Videira-SC
}

Nilson Cesar Fraga*

\begin{abstract}
Resumo:
O presente trabalho consiste em apresentar as transformações socioeconômicas, ocasionadas pela fusão entre a Perdigão e a Sadia no ano de 2009 na cidade de Videira-SC, bem como um breve histórico da formação histórica e social da região Meio-oeste catarinense, inerentes para a compreensão do processo de surgimento da agroindústria local, a Perdigão S/A. Para tanto, fez-se necessário um levantamento bibliográfico e pesquisa sobre dados econômicos e socais de Videira-SC para constatar as mudanças ocorridas ao longo dos anos posteriores à fusão. Nesse sentido, a pesquisa buscou averiguar as consequências da fusão para população videirense ao trabalhar com dados socioeconômicos que irão revelar as transformações locais.
\end{abstract}

Palavras-Chave: Transformação. Socioeconômico. Agroindústria. Fusão. Videira-SC.

\section{Abstract:}

The present work consists in presenting the socioeconomic transformations caused by the merger between Perdigão and Sadia in 2009 in the city of Videira-SC /SC, as a brief history of the historical and social formation of the region of Santa Catarina, to understand the process of emergence Of the local agroindustry, Perdigão S / A. In order to do so, it was necessary a bibliographical survey and research on economic and social data of Vine to verify the changes occurred during the years after the merger. In this sense, the research sought to investigate the consequences of the merger for the Vitorian population by working with socioeconomic data that will reveal local transformations.

Keywords: Transformation. Socioeconomic. Agribusiness. Fusion.Videira-SC.

\section{Introdução}

Para analisar o processo histórico de ocupação em um determinado lugar, é preciso compreender também a formação socioeconômica como consequência das ações e relações homem/meio em determinado período. É nessa direção que a presente pesquisa buscou investigar a dinâmica ecônomica, social e urbana no município de Videira-SC, no estado de Santa Catarina, sobretudo após a fusão entre a Perdigão e a Sadia em 2009, bem como a formação agroindustrial na região do Vale do Rio do Peixe. Como forma de averiguar as

\footnotetext{
*Doutor em Meio Ambiente e Desenvolvimento pela Universidade Federal do Paraná. Docente do Departamento de Geociências da Universidade Estadual de Londrina e do Programa de Pós-graduação (M/D) em Geografia da Universidade Federal do Paraná.
} 
transformações que este setor promoveu em Videira-SC, considerou-se ao longo da pesquisa dois períodos como relação temporal: um anterior e outro posterior à fusão entre Sadia e Perdigão, originando a BRF (Brasil Foods S/A).

São esses dois momentos na formação histórica doMunicípio que deram suporte para explorar e observar as influências econômicas e sociais da agroindústria no que se refere às mudanças ocasionadas pela mesma no espaço geográfico municipal, indo desde os setores sociais, como a mão de obra, até a infraestrutura da cidade para atender às necessidades da chegada de matéria-prima e escoamento da mercadoria.

\section{Um Território Marcado}

Para compreender a complexidade das relações que a agroindústria estabeleceu no município de Videira-SC é preciso discorrer sobre o conceito de terrítorio como maneira de compreender as relações de poder político, econômico e social que é exercido ao longo de décadas em Videira-SC, como também nos municípios vizinhos.

A partir do momento que o homem projeta algum tipo e trabalho sobre o espaço, incia uma relação de poder que irá originiar atividades econômicas de exploração natural e humana (RAFFESTIN, 1993). Tal relação de poder com fins lucrativos na região do Vale do Rio do Peixe, teve início no final do século XIX e início do século XX com a construção da Estrada de Ferro São Paulo - Rio Grande (EFSPRG). O mapa 1, a seguir, representa a localização do município de Videira-SC e também a Estrada de Ferro São Paulo - Rio Grande estará destacada. 
Figura 1 - Localização do município de Videira-SC

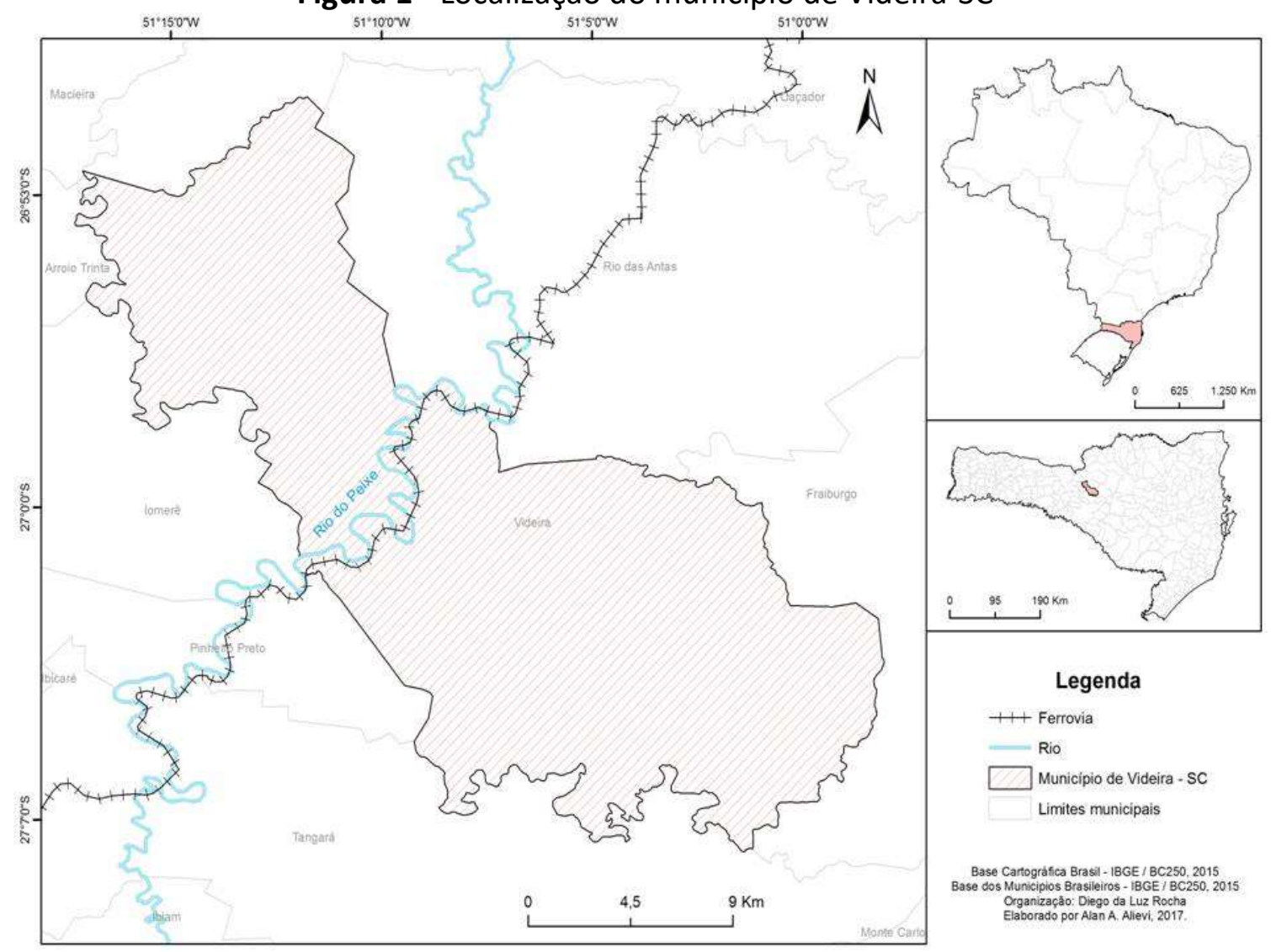

Fonte: Adaptado da Base Cartográfica do Brasil (IBGE, 2015).

No mapa 1 é possível observar o município de Videira-SC, bem como o Rio do Peixe e Estrada de Ferro São Paulo - Rio Grande. Videira-SC se localiza no Oeste do estado de Santa Catarina e na microrregião de Joaçaba-SC.

As estradas de ferro representaram uma evolução espetacular ao sistema capitalista em expansão no século XIX, sendo símbolo do maior progresso e desenvolvimento tecnológico da época. De acordo com Espig (2008) a primeira ferrovia brasileira foi organizada e construída por Irineu Evangelista de Souza, o Barão de Mauá, ligando o Rio de Janeiro a Petrópolis. "Faltava à elite brasileira, entretanto, o capital a ser investido na construção dos caminhos de ferro, cujos valores eram altíssimos. Não tardou para que o capital internacional dominasse os negócios [...] de Estradas de Ferro em nosso país." (ESPIG, 2008, p.152). Mas para que isso acontecesse, entrou em vigor um sistema de concessões, privilégios e subvenção quilométrica como forma de atrair capitais estrangeiros, seja inglês, francês, belga ou alemão.

A posição da União, ao entender que a constituição de ferrovias eram importante para o desenvolvimento econômico brasileiro, foi fundamental para as negociações, havendo variados benefícios para as empresas. Além disso, segundo Espig (2008, p.153), a “União ainda assumia ferrovias privadas à beira da falência ou arrendava-as por valores módicos em busca 
de atrair e preservar os investimentos estrangeiros", mesmo que o custo fosse bastante alto. Na construção da EFSPRG observa-se que a concessão foi feita pela União à João Teixeira Soares, um privilégio de 90 anos e de $30 \mathrm{~km}$ para cada face da ferrovia. A garantia de juros, por sua vez, era efetiva, livre de qualquer imposto e seria paga a cada semestre durante 30 anos (ESPIG, 2008).

A política de subvenções gerou problemas gravíssimos. Se quanto maior a quilometragem, maior a subvenção, os construtores passaram a ampliar indevidamente as linhas, dando à população brasileira ferrovias sinuosas, excessivamente extensas, cheias de curvas, nas quais os trens circulavam de forma lenta e onde a possibilidade de acidentes se potencializa.

\begin{abstract}
Das janelas dos trens, em certas ferrovias, costumavam distrair-se os passageiros, por desfastio, nas longas viagens, com essas aberrações com que se alongavam os traçados para aumentarem os proventos de auxílios oficiais. [...] Trechos numerosos da antiga Rêde Sul-Mineira, da Mogiana e da São Paulo - Rio Grande, constituíam outros tantos frutos destes "malsinados processos" que só interessavam financeiramente a companhias ou a empreiteiros sem escrúpulos, a cuja ganância, se não fechava os olhos, não opunha o Estado um sistema de freios, por um controle mais eficaz das obras de abertura das ferrovias. [...] Mais dia, menos dia, teria o Estado de refazer os trechos, por meio de traçado novo. Mas que importavam estes desvios das condições técnicas? O essencial - construir a linha rapidamente e receber maior auxílio, fora realizado... (AZEVEDO, 1958, p.136-137).
\end{abstract}

Meirinho (2012, p.40) destaca que os investimentos norte-americanos e britânicos ampliaram a implantação de estruturas de transporte e circulação de mercadorias.

\begin{abstract}
As iniciativas se apresentavam na forma de um projeto de desenvolvimento que prometia viabilizar o exercício de atividades mais dinâmicas no interior do país. Ficariam para trás os tempos do limitado comércio dos tropeiros, lentos e vulneráveis. Além disso, a política avançava: no começo do século XX, o Brasil já tinha abolido o trabalho escravo e era uma República. No entanto, olhando com mais atenção é possível observar que o projeto de modernização se revelou uma promessa não cumprida, na qual a população deu a sua parte, mas não encontrou nenhum retorno.
\end{abstract}

A imigração e a colonização de terras servidas pelas linhas férreas foi um dos destaques do Decreto Imperial que regulamentou a criação da EFSPRG. Espig (2008, p.117) aponta se tratar de "um verdadeiro plano de colonização embutido na concessão da EFSPRG e que, caso fosse concluído, teria modificado as condições históricas de colonização da zona servida pela ferrovia em questão." Cabia à Companhia estabelecer em terras demarcadas até dez mil famílias de agricultores nacionais e estrangeiros em um prazo máximo de quinze anos, sendo que cada família teria direito a um lote de terra de dez hectares e uma casa construída. 
De acordo com o Decreto, enquanto o sustento dos imigrantes e colonos fosse provido pela Estrada de Ferro, os mesmos trabalhariam 15 dias por mês em seus lotes e os demais dias para a Companhia, mediante um salário acordado entre as partes, ao passo que as despesas feitas pela empresa com os colonos seriam cobradas em prestações anuais ou semestrais, taxadas em $5 \%$ ao ano e concedendo-se um título provisório aos chefes da família que seria substituído pelo definitivo com a quitação da dívida. À Companhia, cabia ainda construir escolas e igrejas nos núcleos que ultrapassassem trinta famílias.

O governo estabelecia, segundo Espig (2008, p.118) que “15\% das famílias poderiam ser nacionais, enquanto que as outras seriam compostas de imigrantes europeus ou das possessões portuguesas e espanholas," que chegassem ao país por conta própria ou por conta do governo. Em 1890, um novo decreto modificou a concessão original estabelecendo que o capital garantido seria de trinta contos de réis por quilômetro construído, a zona de concessão passaria a $15 \mathrm{~km}$ de cada lado do eixo e os prazos passaram a contar a partir da data de novação do contrato (ESPIG, 2008).

Poucos dias após a assinatura do decreto, Teixeira Soares rumou à Europa em busca de fundos para a constituição de uma empresa capaz de construir a EFSPRG. Constituiu a Compagnie Chémins de Fer Sud-Ouest Brésiliens, associando-se aos banqueiros de Paris e Bruxelas, para quem transferiu a concessão. O engenheiro lançou uma série de títulos no mercado parisiense em 1890, mas o negócio foi mau sucedido (ESPIG, 2008).

Depois de uma série de novos decretos e maus negócios, é sabido que o americano Percival Farquhar adquiriu a EFSPRG, incorporando-a à Brazil Railway Company no início do século $X X$, depois de demonstrar especial interesse na construção de uma linha férrea PanAmericana. Espig (2008) mostra uma divergência bibliográfica com relação à incorporação da EFSPRG, pois enquanto alguns defendem que esta ocorreu em 1906, outros a colocam para o ano de 1908, uma discordância que se deve a dois fatores fundamentais, sendo: a carência de fontes documentais que esclareçam claramente o processo de aquisição da EFSPRG e o fato de que a aquisição aconteceu paulatinamente, mediante negociações de ações. Sendo a BRC uma holding, não operava diretamente às concessionárias de serviço público, apenas possuía ações suficientes para garantir sua direção. Na EFSPRG, "o Sindicato Farquhar detinha em 1910, 42.700 ações, além do arrendamento da linha." (ESPIG, 2008, p.133).

Depois de inúmeros decretos do Governo Provisório, as obras iniciaram. Entre os anos de 1904 e 1905, a linha original com 599 quilômetros foi aberta ao tráfego. Nessa mesma época, o então ministro da Viação e Obras Públicas, o catarinense Lauro Müller, promoveu a 
vinda ao Brasil do empreendedor norte-americano Percival Farquhar, fundando a Brazil Railway Company, empresa que tomou posse do controle acionário da Companhia Estrada de Ferro São Paulo - Rio Grande. Para Scapin (1996), depois de assumir as obras, Farquhar acelerou as forças de trabalho, mas percebeu que não conseguiria cumprir a obra no prazo, solicitando um prazo maior. O governo concedeu-lhe mais três anos para a conclusão dos trabalhos por considerar a ferrovia uma obra estratégica.

No final de 1909, os esforços se concentraram no trecho que se construiriam depois as estações de Rio das Pedras (Videira-SC) e Pinheiro Preto, onde foi construído o único túnel da linha. Somente em 10 de maio de 1910 o trecho até Pinheiro Preto foi aberto e entregue ao tráfego. Na ocasião, foram entregues as estações de Rio Caçador, Rio das Antas, Rio das Pedras e Pinheiro Preto.

A construção da EFSPRG no trecho entre União da Vitória e Marcelino Ramos (RS) se estendeu por dois anos, percorrendo o Vale do Rio do Peixe, no Meio-oeste catarinense. Mas o preço foi alto. De acordo com Queiroz (1966), a estrada obteve uma concessão de terras equivalentes a uma superfície de quinze quilômetros para cada lado do eixo, ou igual ao produto da extensão quilométrica da estrada multiplicada por 18. A área total deveria ser escolhida e demarcada sem considerar sesmarias ou posses, dentro de uma zona de quinze quilômetros para cada lado. Fraga (2010) mostra que para colonizar as terras recebidas como pagamento pela construção, a Brazil Railway tratou de colocar para fora de seus domínios todas as pessoas que ocupavam terras sem possuir títulos de propriedade a partir de 1911. Embora seja possível dizer que a iniciativa, bem como a concessão feita à companhia, contrariavam a Lei de Terras de 1850, é preciso ressaltar, que estas foram subvenções do governo brasileiro à companhia construtora, conforme previsto em decreto. Assim, o governo paranaense (cujo vice-presidente do Estado, Affonso Camargo, era advogado da Brazil Railway) reconheceu os direitos da empresa. "Aos posseiros que ousava se opor às medidas de despejo, a Brasil Railway enviava elementos de seu corpo de segurança, que contava com 200 homens armados." (FRAGA, 2010, p.123).

No mesmo ano, com o intuito de explorar as terras obtidas às margens da ferrovia, a Brazil Railway criou uma nova companhia subordinada: a Southern Brazil Lumber and Colonization Company. Ela e a Brazil Development \& Colonization Company "protagonizaram as grandes transformações após a inauguração da ferrovia na região do Contestado." (VALENTINI, 2009, p.115). 
Percebe-se o esforço do governo estadual de "ocupar" o Oeste catarinense no momento que ingora a existência de uma população cabocla, tendo interesses bem claros, quando concede essas terras à Brazil Railway: a) eliminar a população mestiça de caboclos; b) incentivar a migração de italianos e alemães para o Oeste de Santa Catarina; c) explorar as riquezas naturais, especialmente, a madeira de lei. A forte propaganda governamental detalhava a região Meio-oeste catarinense como sendo de solo fértil, destacando a estrade ferro e o Rio do Peixe como elementos crucais do desenvolvimento de atividades econômicas (PERTILE, 2008).

\section{O Desenvolvimento Agroindustrial (In)Completo}

Já no final da década de 1910, com o fim da Guera do Contestado, os primeiros migrantes italianos, vindos do Rio Grande do Sul, chegavam na região Meio-oeste de Santa Catarina, com intuito de adquir um pequeno lote de terra para iniciar as atividadades econômicas.Espíndola (2002), pontua que, entre 1910 a 1950, o governo catarinense concedeu terras para várias empresas colonizadoras que ficavam encarregadas de dividir as terras do Oeste de Santa Catarina em pequenos lotes de 200 a 300 metros de largura e 1 km de profundidade, que seriam vendidos aos migrantes italianos e alemães do Rio Grande do Sul.

Vale ressaltar o que era desenvolvido no interior das propriedades, que, segundo Espíndola (2002, p. 28):

\footnotetext{
No interior dessas pequenas propriedades os produtores plantam milho, alfafa, trigo, feijão, mandioca, criam porcos, galinhas, e desenvolvem a colheita da ervamate e a extração da madeira. Paralelamente, confeccionam suas casas, seus galpões, suas ferramentas de trabalho, entre outras. Trata-se, portanto, da constituição do complexo rural sul brasileiro, predominantemente de pequenos produtores mercantis de origem européia.
}

Na contribuição de Espíndola (2002), é possível observar o fortalecimento e o crescimento das vilas situadas nas margens do Rio de Peixe, com por exemplo as Vilas de Perdizes e Vitória, que ao longo de poucos anos obtiveram um expressivo aumento de tamanho com atividades econômicas voltadas para agricultura e a criação de aves e suínos a partir da década de 1920. Mais tarde, as vilas de Perdizes e Vitória se tornariam o município de Videira-SC. É nesse contexto que a região Oeste de Santa Catarina é ocupada com mais intensidade, visto pela forte propaganda. Muitos migrantes foram direcionados para as 
margens do Rio do Peixe, formando pequenos aglomerados (vilas) de pessoas, que se tornariam, mais tarde, as inúmeras cidades do Vale do Rio do Peixe.Na imagem 1, é possível observar as vilas de Perdizes e Vitória em 1917.

Imagem 1 - Vilas de Perdizes e Vitória em 1917.

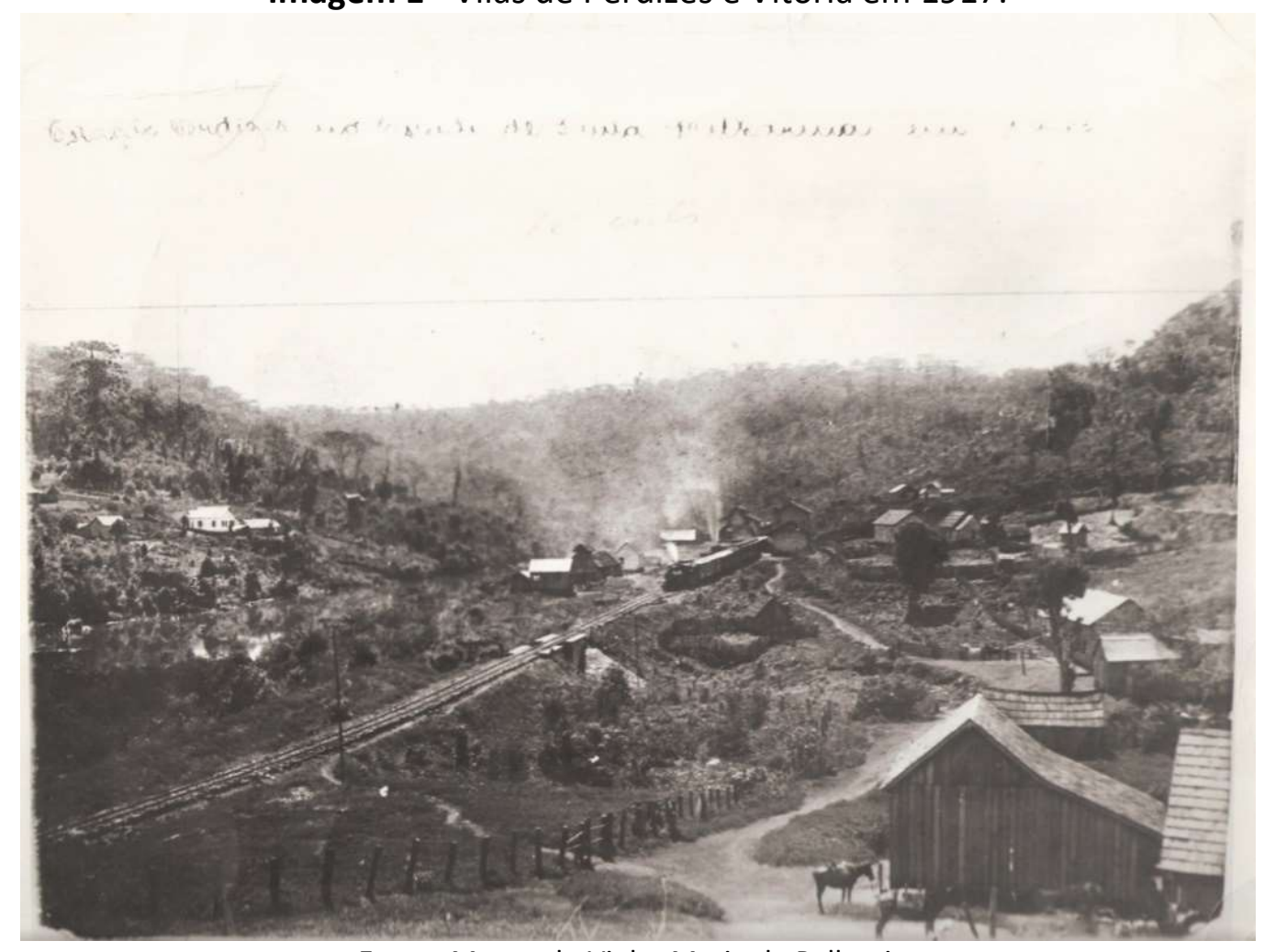

Fonte: Museu do Vinho Mario de Pellegrin.

Com o crescimento das vilas nas margens do Rio do Peixe, formaram-se os municípios que hoje compõem o Vale do Contestado. Perdizes e Vitória, especificamente, uniram-se para formar Videira-SC, município emancipado de Cruzeiro (atual Joaçaba). O novo Município criado em 1944, já se destacava na produção de alimentos processados, derivados de banha e produção de aves e suínos através da Perdigão, inicialmente uma fábrica de banha chamada Companhia Catarinense de Banha. Mattos (1968) deixa claro a importância da indústria de alimentos no Estado, que teve um maior crescimento a partir dos anos 1950, quando os frigoríficos deixaram de ser vistos de maneira isolada e passaram a ser um ramo da indústria catarinense. Pertile (2008, p. 89) contribui quando aborda a questão do fortalecimento da indústria catarinense, ao pontuar:

Já no início da década de 1940, em meio a esse processo de integração, os comerciantes do Oeste de Santa Catarina sentiram que o comércio de suínos vivos, até então lucrativo, começava a dar sinais de arrefecimento devido à dificuldade de competir com os frigoríficos estabelecidos em São Paulo. Desse modo, eles foram pressionados a redirecionar seus empreendimentos comerciais para o abate de 
animais. Começaram, assim, a separar a comercialização de banha e de carne suína. Com a necessidade de mudança no perfil do produto, originam-se os primeiros abatedouros na região, via associação e expansão de capitais comerciais locais. Inicialmente, ocorreu no Vale do Rio do Peixe, que possuía maior intercâmbio comercial com o estado de São Paulo.

É nesse momento que as agroindústrias começam a ter destaques estadual e nacional, caracterizando o Oeste catarinense como o maior produtor de carne processadas do Brasil (GOULARTI FILHO, 2007). Alguns dos incentivos foram cruciais para que o produto que era fabricado no Oeste do Estado chegasse em diversas cidades brasileiras. Exemplo disto foi o investimento do governo na infraestrutura da região, construindo estradas e aquilo que fosse necessário para o funcionamento industrial e escoamento de produtos. A estes investimentos também se deveo crescimento na produção de suínos dos anos 1940 para 1950 que superou os $60 \%$.

Espíndola (2002) pontua que o surgimento da indústria da carne do Sul do Brasil, se deu quando o excedente econômico ficava na região, possibilitando que o pequeno agricultor pudesse acumular capital em sua propriedade. Nesse período, o Oeste de Santa Catarina deu início ao processo de beneficiamento de carne no século $X X$, quando migrantes alemães vindos do Vale do Itajaí se instalaram na região, tendo participação dos italianos vindo do norte do Rio Grande do Sul.

Na década de 1930, com aquisições de moinhos de trigo e pequenos frigoríficos e outros empreendimentos na região do Oeste catarinense, inicia-se o crescimento da Perdigão, que ia desde a criação de suínos até o processamento de carne (salame), como também o armazenamento de banha (TASSARA, 1996).

A Perdigão era uma empresa familiar e tradicional, que segundo Chandler (1988, p. 3):

\footnotetext{
Era formada por uma única entidade. Nela um ou vários proprietários dirigiam uma casa comercial, uma fábrica, um banco ou um serviço de transportes a partir de um único escritório. Em geral este tipo de empresa desempenhava uma única função econômica, para uma só categoria de produtos e numa determinada região geográfica.
}

Entre as décadas de 1940 e 1960, a Perdigão vivenciou um grande avanço em alguns setores, como por exemplo: a construção da fábrica de ração para granja, cuja produção era direcionada para os produtores que forneciam os animais para abate; melhoramento genético das aves e suínos; implantação de uma política de controle de qualidade para os integrados, o que permitiu o aumento de produção de aves, vinculado aos pequenos produtos. Nesse 
período, a Perdigão já tinha se tornado um complexo de empresas interligadas, deixando de ser tradicional para ser uma empresa moderna e com nível de tecnologia empregada muito alto (TASSARA, 1996). Na imagem 2 é possível observar a unidade indústrial da Perdigão na década de 1980.

Imagem 2 - Unidade industrial da Perdigão na década de 1980

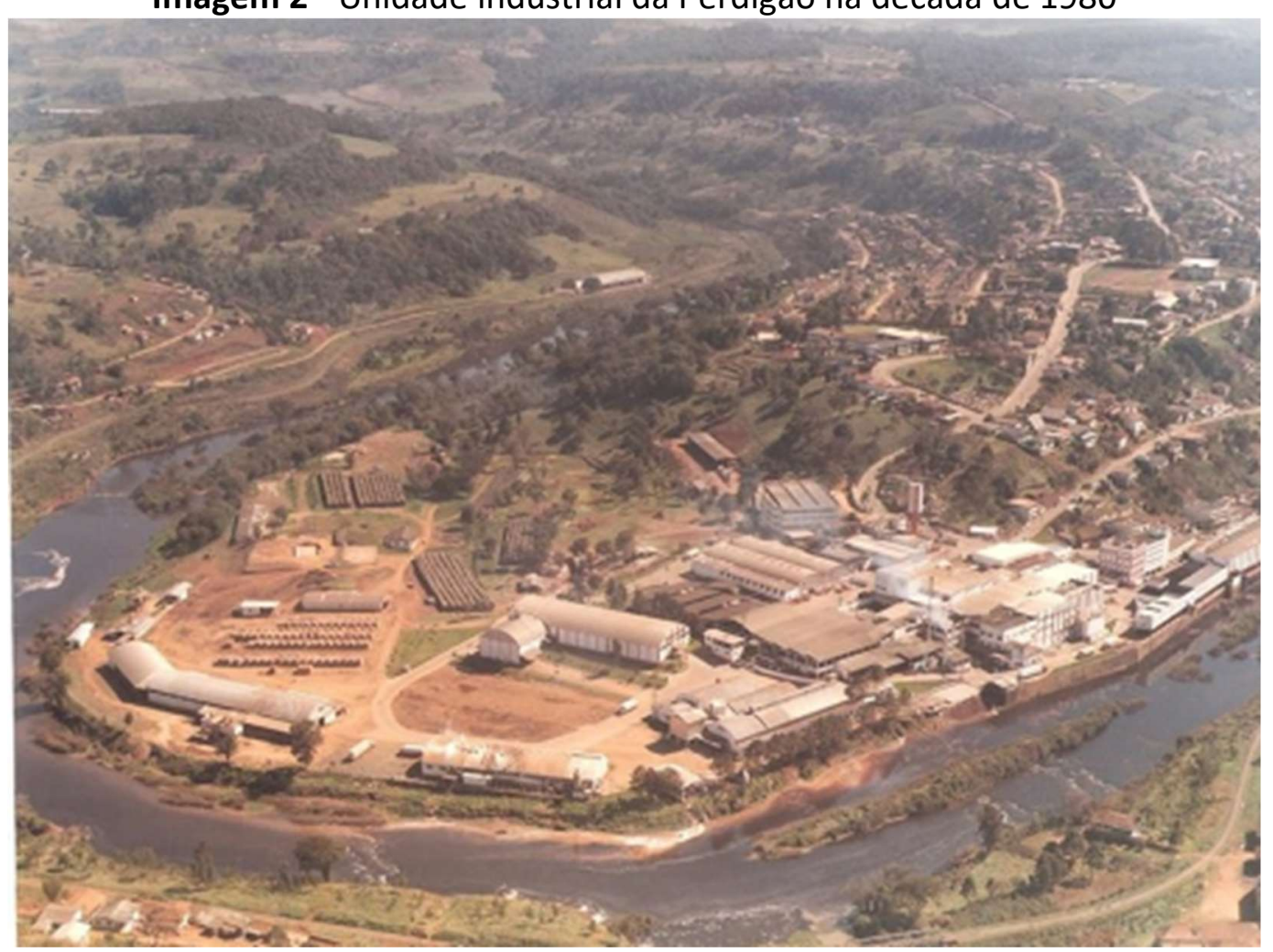

Fonte: Museu do Vinho Mario de Pellegrin.

Todos esses investimentos e mudanças na sua estrutura industrial, tinham como objetivo o aumento da produção de derivados dos suínos e aves para atender o mercado de Santa Catarina e Brasil. Nesse ritmo de crescimento, a Perdigão já atuava com granjas, abatedouros, frigoríficos, fábrica de banha, curtume, fábrica de ração, moinhos, fábrica de caixas, madeireira, postos de vendas, aeroporto e filiais pelo país. Outro ponto que merece destaque no que se refere aos benefícios que a empresa trouxe para região Oeste de Santa Catarina foi o investimento no sistema de transporte, sobretudo em rodovias (boa parte com investimentos do governo estadual) e aéreo, justamente para escoar suas mercadorias para São Paulo e outros estados brasileiros. Com o melhoramento das rodovias na década de 1950, o transporte aéreo de mercadorias deixou de ser o principal, fazendo com que, até atualmente, a empresa utilizasse mais caminhões (TASSARA, 1996). 
Mediante a essas transformações na dinâmica da produção local que a agroindústria ocasionou, é importa destacar o que Pertlie (2008, p. 184) afirma:

\begin{abstract}
A dinâmica de reorganização da divisão social do trabalho, que desloca trabalhadores para as cidades, vai constituir um mercado regular de gêneros alimentícios, impulsionando uma especialização espacial de atividades e um incremento na escala produtiva e na produtividade do trabalho. O Oeste catarinense insere-se no novo arranjo territorial como produtor de alimentos, ligado à comercialização e industrialização de suínos e aves. Nessas circunstâncias, alguns municípios possuem as unidades industriais e atraem população de diversos outros municípios principalmente para trabalhar em seus frigoríficos. Suas cidades têm apresentando importante ritmo de crescimento em termos populacionais e econômicos, possibilitando o desenvolvimento de uma maior infraestrutura. Como exemplo dessas cidades tem-se Chapecó, Concórdia e Videira-SC.
\end{abstract}

De fato é importante destacar o que Perroux (1967) pontua sobre as ações de indústrias dominantes, exercendo tipos de ações específicas sobre outras empresas e também na economia. O autor defende que "o crescimento não surge em toda parte ao mesmo tempo; manifesta-se com intensidades variáveis, em pontos ou polos de crescimento; propaga-se, segundo vias diferentes e com efeitos finais variáveis, no conjunto da economia." (PERROUX, 1967, p. 164).

Segundo Souza (2005, p. 96):

Uma política de desenvolvimento com base em polos de crescimento não deve centrar-se apenas na implantação da indústria motriz em determinada região, mas precisa incentivar também o surgimento de atividades satélites, fornecedoras de insumos para a atividade principal.

As indústrias satélites que Souza (2005) aborda consistem justamente no que a Perdigão fez, tendo inúmeras indústrias prestando serviços para indústria motriz. Com a presença de indústrias no território e as relações socais estabelecidas pelo advento de empresas, permite-se falar em polos de desenvolvimento quando uma região tem crescimento econômico acentuado devido à concentração de indústrias sem se expandir para todo território nacional, ficando em algumas localidades propícias à instalação (ANDRADE, 1973). Mas, para que esse polo se mantenha sendo fator de desenvolvimento e atração de empregos, são necessárias algumas medidas para conceber resultados que venham beneficiar o local e a região. Segundo Andrade (1973, p. 54):

Assim, se observa que os efeitos motrizes da indústria não são permanentes e que em consequência, uma indústria que hoje provoca o aparecimento de um polo, se ela não se renova, não dá margem ao surgimento de uma série de outras indústrias que mantenham a dinamização por ela desencadeada, fará com que o polo 
desapareça gradativamente, que a sua função polarizadora vá sendo absorvida por outros centros, por outros polos. Em geral a indústria motriz em sua ação de obtenção de matérias-primas, de ponto de atração para mão de obra e de produtora de um ou de uma série de produtos dinamiza a vida regional provocando a atração de outras indústrias, criando aglomerações de população que estimulará o desenvolvimento das atividades agrícolas e pecuárias nas áreas fornecedoras de alimentos e de matérias-primas e desenvolve a formação de atividades terciárias proporcionais às necessidades da população que a cerca, que se instala em sua área de influência.

A Perdigão exerce sobre o território o que a indústria motriz faz, segundo Andrade (1973): obtém a matéria-prima através dos integrados e estimula atividades agrícolas e pecuárias. Sendo assim, a maior agroindústria do município de Videira-SC, é um polo de crescimento, pois: "provocam o crescimento do produto e da renda per capta sem acarretar transformações sensíveis às estruturas regionais" (ANDRADE, 1973, p. 55-56).

O programa de integração que a Perdigão executa com seus produtores é interpretado como uma das características de indústria motriz, muito utilizada no Oeste catarinense.

Com o crescimento das vendas de carnes processadas para o mercado interno e externo foi necessário aumentar a produtividade de aves e suínos nas empresas agroindustriais. Foi na década de 1960 que o sistema integrado de produção teve seu início, ocasionando uma série de consequências.

[...] pode-se afirmar que, de uma forma geral, as empresas integradoras, por um lado, disponibilizam recursos, na forma de insumos (rações, reprodutores suínos, sementes, pintinhos de corte, etc) e assistência técnica, o que, com o trabalho do produtor, irá garantir a produtividade e qualidade necessária (e exigidas) pelas empresas. Por sua vez, o produtor integrado participa no ciclo produtivo com as suas instalações, mão de obra e outros custos, tais como a energia elétrica consumida no processo produtivo, água, etc. (PERTILE, 2008, p. 99).

Percebe-se que o sistema de integração praticado pelas agroindústrias Perdigão e Sadia no período anterior à fusão, bem como sua forma de gestão constituindo polos de desenvolvimento, permitem compreender a existência de um poder simbólico exercído pela organização sobre a vida das pessoas, as quais passam a depender do polo agroindustrial em maior ou menor escala.

É importante ressaltar de qual maneira a financeirização da economia possibilitou a fusão entre Sadia e Perdigão em 2008. Na década de 1990, a globalização da economia mundial estava em um estágio bastante avançado, logo, houve uma abertura das economias dos países para investimentos de acionistas, sendo que, nesse mesmo período, aumentou os 
investimentos de acionistas em diversas empresas do Brasil, pois, muitas indústrias de gestão familiar, começa a ter uma gestão corporativa com o capital aberto . Segundo Miranda (2013, p. 12-13):

Com o fim dos obstáculos que separavam os mercados nacionais dos estrangeiros. O fim dessas restrições se consubstanciou na liberalização dos fluxos de capital, o que permitiu o aproveitamento dos diferentes de câmbio de juros entre países e o desenvolvimento do mercado de securities e de capitais. Esse processo resultou na criação de novos produtos financeiros, na redução do controle sobre a movimentação do capital e na integração dos mercados financeiros, com o aumento de aplicações estrangeiras nas bolsas nacionais.

Como afirma Miranda (2013), o fluxo de capital teve um aumento considerável entre países do mundo, como tabmém na integração entre mercados, ou seja, efeitos da globalização que afetava a parte financeira dos países. Fortalecia, nesse cénario econômico, o poder dos acionistas sobres as empresas, sobretudo no que se refere na gestão das empresas nacionais, que é o caso da Sadia e da Perdigão. Ainda Miranda $(2013$, p. 11) sustenta que as transformações ocasionadas pela financeirização da economia, têm resultados em escala micro e na macroeconômico, sendo que:

\begin{abstract}
O sistema financeiro, além de ser uma das fontes de recursos para o investimento, passa a ser uma fonte de valorização e ampliação do capital e da riqueza. Consequentemente, esse processo influencia o padrão de financiamento, a estrutura de capital, o investimento, a produção, o consumo, a poupança, a gestão das organizações e o sistema de governança corporativa. Ou seja, a financeirização implica em mudanças de ordem micro e macroeconômica. Para que a financeirização tenha se tornado a forma de acumulação dominante foram necessários novos arranjos institucionais, diferentes daqueles que prevaleceram na era do fordismo. A financeirização é o novo regime de acumulação da economia, definido pela subordinação das atividades produtivas ao interesse do capital financeiro. A adoção da maximização da riqueza do acionista como modelo de governança é uma das dimensões desta nova forma de acumulação, que afeta a gestão das empresas. Sob este modelo de governança as empresas passam a focar o crescimento de curto prazo, relacionado a seu valor no mercado de capitais, em detrimento do crescimento de longo prazo via investimentos produtivos, o que restringe o crescimento econômico do país. Esta estratégia afeta sua estrutura patrimonial, elevando sua fragilidade às mudanças adversas nas expectativas dos preços dos ativos, financeiros e de capital, e da taxa de juros. Portanto, a financeirização possui impactos microeconômicos, traduzidos pelo padrão de financiamento de pela estrutura financeira das empresas, que resultam em efeitos macroeconômicos.
\end{abstract}

Contudo, as mudanças foram muitas, desde na nova forma de acumulação de capital até o baixo investimento físico. A financeirização tem como resultado alguns efeitos negativos na microescala, pois os acionistas investes em ações numa determinada empresa que já tem unidades industriais pelo País, mas deixam de aplicar medidas que venham a melhorar tais 
unidades, priorizando, conforme Miranda (2013), o acúmulo de capital o aumento de suas ações.

Considerando o crescimento da empresa e a financeirização da economia brasileira nos anos de 1990, aliados à grande crise financeira e de gestão vivida pela Perdigão na mesma década, pode-se afirmar que a fusão com a Sadia em 2009 - que também enfrentava problemas de ordem financeira em função da crise de 2008 - consituiu-se em uma estratégia empresarial promovida pelos acionistas, que precisariam resgatá-las como forma de obter maiores lucros e reduzir os prejuízos acumulados ao longo dos anos.

A crise de 2008 vem como ponto principal para finalizar as negociações da fusão entre a Sadia e a Perdigão, pois, os reflexos desse ano no segundo setor da economia brasileira foram tão negativos, que, praticamente todos os seguimentos da indústria foram afetados. $\mathrm{O}$ setor alimentício não ficou de fora, as ações da Sadia caíram muito e, para não ter mais prejuízos, a fusão foi concretizada em 2009, agora, com acionistas nacionais e estrangeiros.

Para compreender mais sobre fusão é importante ressaltar o conceito, que:

\begin{abstract}
A fusão de empresas é o negócio plurilateral que tem por finalidade a união das ações de duas ou mais sociedades na forma de uma nova sociedade, que thes sucederá em todos os direitos e obrigações, ou seja, implica sucessão universal, com a extinção das empresas anteriores fusionadas, e está descrita na lei $n^{\circ} 6.404 / 76$ no art. 228 (SANTOS; SCHMIDT; FERNANDES, 2003, p. 302-303).
\end{abstract}

\title{
As Consequências para Videira-Sc: O Emprego e a Falta Dele
}

Para além dos acionistas, a população videirense e de vários outros municípios do Meio-oeste catarinense atua como mão de obra empregada na agroindústria, hoje BRF. Considerando o pessoal ocupado por setor, vê-se no quadro abaixo como o número de empregos oscilou na indústria no início dos anos 2000, antes que a fusão com a Sadia ocorresse, mas mantendo uma projeção de crescimento. A isto, soma-se o crescimento do setor de serviços e a manutenção de uma curva de crescimento constante no comércio. 
Gráfico 1 - Pessoal em Videira-SC 2002-2015

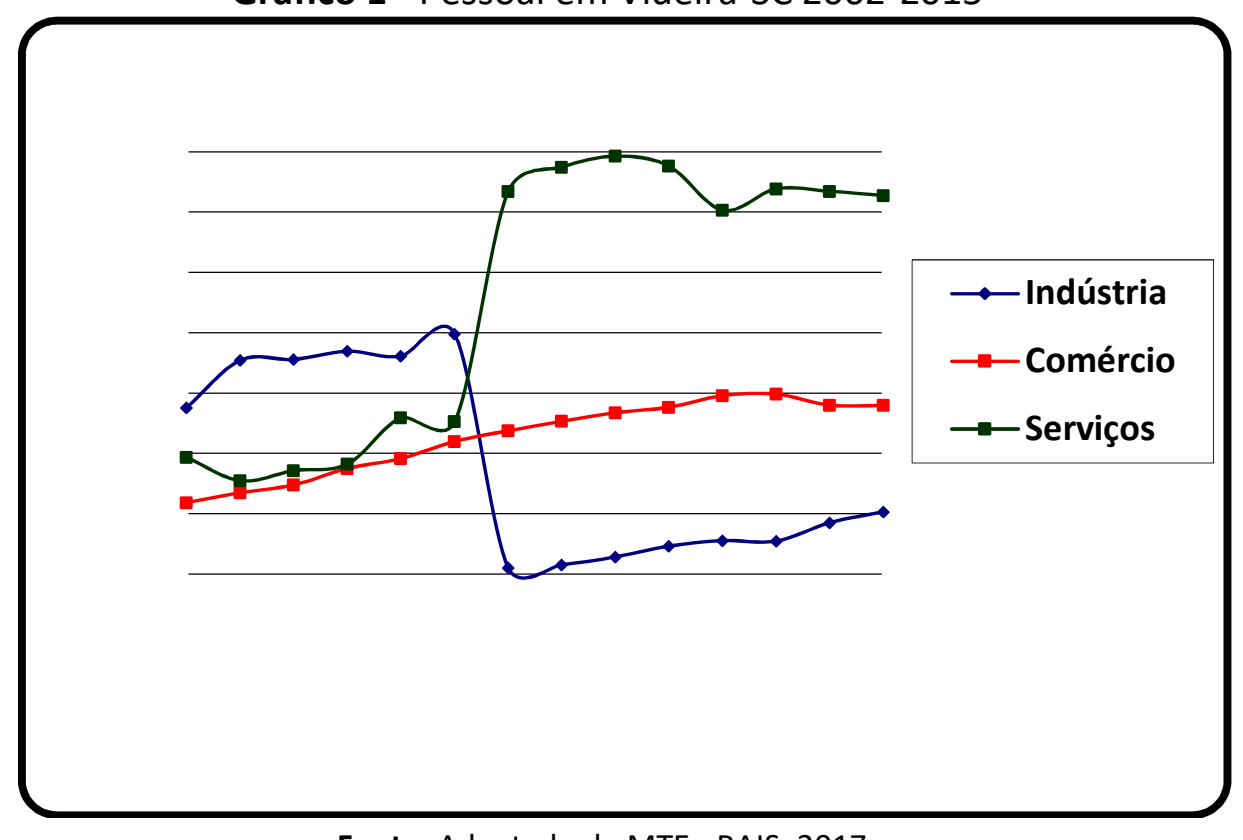

Fonte: Adaptado de MTE - RAIS, 2017.

No período posterior à fusão, nota-se a existência de uma vertiginosa queda no número de pessoas empregadas na indústria com uma queda de 3874 empregos em apenas um ano. Mesmo que nos anos seguintes tenha-se registrado um pequeno aumento de pessoal ocupado, observa-se que tal crescimento não foi significativo para reverter a forte queda em 2008 e 2009, ou seja, a indústria de alimentos videirense não conseguiu se reerguer em seis anos no requisito de geração de empregos no setor alimentício, tendo pequenas elevações até 2015.

Enquanto isso, o setor de serviços cresce assustadoramente, com o emprego de mais 3818 pessoas no mesmo período em que há queda no número de empregos na indústria. Enquanto estavam havendo as negociações da fusão entre a Sadia e a Perdigão até o ano do anúncio da fusão em 2009, fica claro que o setor de serviços videirense foi o que mais se beneficiou nesse sentido, mas que ao longo dos anos seguintes, vem apresentando pequenas oscilações no número de pessoal ocupado, sobretudo nos últimos três anos, entre 2013 a 2015.

No setor de comércio de Videira-SC, o número de pessoal ocupado no ano da fusão em 2009 não apresentou reduções, mantendo um crescimento de pouca intensidade, como é possível observar no gráfico acima. Vale chamar atenção que a partir do ano de 2014 é possível observar a queda no número de pessoas vinculadas ao setor de serviço videirense. 
Quando se trata desses três setores da economia de Videira-SC e, analisando os três gráficos acima, percebe-se que a indústria de alimentos foi o que mais sentiu e de maneira negativa as consequências da fusão em 2009 e nos anos seguintes, pois há pouca expressividade quanto ao número de pessoal ocupado. Ao mesmo tempo, o setor de serviços foi o que teve maior crescimento com a fusão no sentido de pessoal ocupado e na participação econômica no PIB municipal. Já o comércio teve crescimento pouco expressivo, se comparado ao de serviços, ou seja, o único setor que mais sobressaiu após a fusão foi o de serviços. Seguindo a queda de empregos, reduziu-se a participação industrial no PIB municipal em 17,9\% de 2009 a 2013, segundo dados do IBGE (2010). No quadro 1, é possível analisar o número de pessoas ocupadas nos três setores da economia videirense, observando que a indústria de alimentos apresentou uma queda a partir de 2008, ano em que a crise hipotecária norte-americana afetou o Brasil.

Quadro 1 - Pessoal ocupado nos três setores da economia de Videira-SC

\begin{tabular}{|l|c|c|c|}
\hline A n o & Indústria de Alimentos & Comércio & S e r v i ç o \\
\hline $\mathbf{2 0 0 2}$ & 3.756 & 2.182 & 2.933 \\
\hline $\mathbf{2 0 0 3}$ & 4.542 & 2.347 & 2.545 \\
\hline $\mathbf{2 0 0 4}$ & 4.557 & 2.477 & 2.713 \\
\hline $\mathbf{2 0 0 5}$ & 4.692 & 2.748 & 2.821 \\
\hline $\mathbf{2 0 0 6}$ & 4.609 & 2.915 & 3.591 \\
\hline $\mathbf{2 0 0 7}$ & 4.977 & 3.196 & 3.525 \\
\hline $\mathbf{2 0 0 8}$ & 1.103 & 3.374 & 7.343 \\
\hline $\mathbf{2 0 0 9}$ & 1.153 & 3.533 & 7.743 \\
\hline $\mathbf{2 0 1 0}$ & 1.283 & 3.673 & 7.926 \\
\hline $\mathbf{2 0 1 1}$ & 1.461 & 3.763 & 7.761 \\
\hline $\mathbf{2 0 1 2}$ & 1.552 & 3.956 & 7.029 \\
\hline $\mathbf{2 0 1 3}$ & 1.545 & 3.982 & 7.385 \\
\hline $\mathbf{2 0 1 4}$ & 1.850 & 3.799 & 7.344 \\
\hline $\mathbf{2 0 1 5}$ & 2.029 & 3.793 & 7.274 \\
\hline
\end{tabular}

Fonte:Adaptado de MTE - RAIS, 2017.

Mas, os resultados poucos consideráveis do crescimento da indústria alimentícia videireinse estão associadosà crise norte-americana de 2008, que teve consequências negativas para a indústrial nacional. Antes mesmo de terminar o ano da crise, a participação 
da indústria no PIB nacional havia sofrido uma queda expressiva, afetando o setor industrial das pequenas, médias e grandes cidades. Em Videira-SC é possível analisar o impacto que a crise hipotecária causou na indústria de alimentos local ao verificar o quadro 2 abaixo:

Quadro 2 - Participação das atividades econômicas no PIB de Videira-SC

\begin{tabular}{|c|c|c|}
\hline Ano & Serviços (\%) & Indústria (\%) \\
\hline $\mathbf{1 9 9 9}$ & 35,0 & 53,7 \\
\hline $\mathbf{2 0 0 0}$ & 34,7 & 53,4 \\
\hline $\mathbf{2 0 0 1}$ & 32,9 & 54,2 \\
\hline $\mathbf{2 0 0 2}$ & 36,4 & 51,6 \\
\hline $\mathbf{2 0 0 3}$ & 35,7 & 51,5 \\
\hline $\mathbf{2 0 0 4}$ & 37,7 & 49,4 \\
\hline $\mathbf{2 0 0 5}$ & 40,7 & 45,9 \\
\hline $\mathbf{2 0 0 6}$ & 43,8 & 44,3 \\
\hline $\mathbf{2 0 0 7}$ & 42,7 & 45,0 \\
\hline $\mathbf{2 0 0 8}$ & 44,1 & 43,3 \\
\hline $\mathbf{2 0 0 9}$ & 44,2 & 43,5 \\
\hline $\mathbf{2 0 1 0}$ & 49,0 & 39,5 \\
\hline $\mathbf{2 0 1 1}$ & 47,4 & 36,6 \\
\hline $\mathbf{2 0 1 2}$ & 49,6 & 36,6 \\
\hline $\mathbf{2 0 1 3}$ & 44,4 & 25,6 \\
\hline
\end{tabular}

Fonte: Adaptado de IBGE, 2012.

Analisando o quadro 2, verifica-se que a indústria a partir de 2008 teve uma redução no PIB municpial, sendo que o serviço aumentou nesse período e nos anos posteriores, fato que não ocorreu com a participação da indústria, mantendo uma queda constante.

Mesmo em 2009, ano da fusão, os resultados de crescimento na nova marca, a BRF, não foram significativos, pois as oscilações nos números de pessoas admitidas,que não era alto, ainda seria ultrapassado pelo de pessoas demitidas, gerando um saldo negativo de pessoas empregadas na indústria alimentícia em Videira-SC. Crises como a crise imobiliária americana de 2008 influenciaram de sobremaneira a indústria brasileira que, atuando no mercado de ações, especulação de ativos e fundos de pensão, precisou recorrer a ações menos ortodoxas como exemplificada pela fusão entre a Perdigão e a Sadia. 
Outro dado importante é que após fusão em 2009, a composição acionária ficou da seguinte maneira: $27,8 \%$ para os acionistas estrangeiros e 21,8 para os nacionais (RELATÓRIO ANUAL, 2015). Isto é, 49,6\% da BRF era composta por acionistas, um dos motivos para explicar a redução do setor industrial de Videira-SC, tanto no número de pessoas admitidas, quanto na participação econômica no PIB municipal. Estas são consequências pelas quais a economia videirense vem passando, fruto da financeirização da economia mundial, como também da crise de 2008 e da crise política brasileira de 2016, que afetou a indústria local.

\section{Conclusão}

Tratar das consequências socioeconômicas de Videira-SC a partir da indústria alimentícia, é uma tarefa fundamental, até para compreender o atual estágio da configuração territorial do Município.Mas, antes de pautar na fusão, é importante destacar que, a crise hipotecária norte-americana de 2008, teve forte influência para concretizar a fusão, assim, como nos resultados socioeconômicos ao longo dos anos, pois, o segundo setor da economia brasileira foi impactado pela crise de 2008. A partir desse momento, pode-se iniciar uma discussão acerta dos dados econômicos e sociais do município de Videira-SC, tendo a fusão como um dos fatores analíticos das oscilações dos dados socioeconômicos videirense.

Após analisar diversos indicadores econômicos da área de estudo e compreender sua dinâmica histórica e social, é possível apresentar o impacto negativo causado pela fusão entre duas das maiores agroindústrias brasileiras, Perdigão e Sadia, em 2009, para o município de Videira-SC. Mediante aos dados analisados, foi possível concluir que houve impactos negativos na indústria e no comércio após o ano de 2009, como também a participação do setor industrial no PIB de Videira-SC apresentou uma redução mais elevada após a fusão entre a Sadia e a Perdigão, caindo de 43,5\% em 2009, para 25,6\% em 2013. Essa redução revela o quanto a indústria deixou de participar economicamente em Videira-SC, obtendo uma porcentagem cada vez menor ao longo de cada ano.

A indústria de alimentos em 2009, apresentou saldo reduzido com relação a 2008 , tanto no número de pessoas admitidas e de pessoas desligadas durante o ano. É fundamental ressaltar que, após a fusão, o saldo de pessoas na indústria de alimentos sempre obteve fortes oscilações, chegando a registrar em 2016 saldo negativo no número de pessoas que mantiveram seu emprego, ou seja, desligou-se muito mais do que admitiu. 
Outro indicador, que reforça o impacto negativo da fusão, foi à participação econômica do setor de serviços no PIB entre 2008 e 2009 com um crescimento de apenas $0,1 \%$.

Esses são indicadores que, ao serem analisados, deixam evidentes as mudanças no setor econômico da cidade de Videira-SC, que interferem diretamente no desenvolvimento da cidade no sentido de ainda depender da forte presença do setor agroindustrial local, agora com a marca Brasil Foods - BRF.

Embora, a unidade industrial da BRF mantenha-se em Videira-SC, atuando na linha de produção de salsichas e na fabricação de ração, é interessante pontuar que após a fusão em 2009, quando houve uma queda no PIB, o mesmo só voltou a crescer de maneira expressiva a partir de 2014. Isso deixa claro que Videira-SC não diversifica a capacidade produtiva no setor industrial, tendo como fator limitador a agroindústria local que polariza esse setor, fazendo com que haja uma dependência de sua estrutura, tanto populacional quanto para outras empresas que prestam serviços para BRF.

Ter uma indústria que polariza a produção, como é caso de Videira-SC na figura da atual BRF, diminui a diversidade de empresas como uma reestruturação econômica local mediante uma crise, como foi o caso em 2008 que, se a indústria alimentícia não gera emprego e nem renda, vários prestadores de serviço para BRF começam sentir os efeitos, podendo gerar um cénario econômico impactando.

Portanto, a financeirização da economia que possibilitou que as empresas vendessem suas ações na bolsa de valores, dando condições para acionistas comprarem-nas, gerou um resultado insatisfatório em microescala, com efeitos negativos a longo prazo. Isto pode ser observado em Videira-SC no momento em que a Sadia compra parte das ações da Perdigão, tendo consequências negativas imediatas na economia e no setor social da cidade, mas ainda apresentando reflexos no decorrer dos anos.

A herança deixada para a cidade que antes era considerada um polo agroindustrial foi a instabilidade econômica no setor industrial, com fortes reflexos no setor social no que tange o índice de empregos e desempregos, revelando que a população videirense deu sua parte empregando a mão de obra e não obteve outro retorno senão a incerteza, o desemprego e a perda de expressividade regional.

Mesmo sabendo que Videira-SC nunca tenha sido cidade de uma única indústria, o papel da grande fábrica empregadora é a marca da organização social, econômica e territorial de municípios como esse, que tem sua vida ereta e difundida a partir do grande capital. Esse 
não é um caso exclusivo, serve bem para entender outros municípios catarinenses e brasileiros demonstrando, indiretamente, que municípios com maior diversidade industrial correm menos risco socioeconômico quando de casos como a fusão registrada em 2009, gerando a BRF.

\section{Referências}

ANDRADE, M. C. A teoria dos polos de desenvolvimento e a realidade nordestina. 3. ed. Recife: Brasiliense, 1973.

AZEVEDO, F.Um trem corre para o Oeste: estudo sobre a Noroeste e seu papel no sistema de viação nacional. 2. ed. São Paulo: Melhoramentos, 1958.

CHANDLER, A. La main visible des managers. Paris: Econômica, 1988.

FRAGA, N.C. Vale da morte: o Contestado visto e sentido. Blumenau: Hemisfério Sul, 2010.

ESPIG, M. J. Personagens do Contestado: os turmeiros da estrada de ferro São Paulo - Rio Grande(1908-1915). 2008. 343 f. Tese (Doutorado em História)-Universidade Federal do Rio Grande do Sul, Porto Alegre,2008.

ESPÍNDOLA, C. J. As agroindústrias da carne do sul do Brasil.2002. 261 f. Tese (Doutorado em Geografia) - Universidade de São Paulo, São Paulo, 2002.

GOULARTI FILHO, A. Formação econômica de Santa Catarina. Florianópolis: UFSC, 2007.

MATTOS, F. M. A industrialização catarinense. Florianópolis: UFSC, 1968.

MEIRINHO, B. C. D. Contestado, a modernização incompleta. In: FRAGA, N. C. (Org.).Contestado em guerra: 100 anos do massacre insepulto do Brasil-1912-2012. Florianópolis: Insular, 2012. p. 27-44.

MIRANDA, B. P. J. Impactos da financeirização sobre a fragilidade micro e macroeconômica: um estudo para a economia brasileira entre os anos de1995-2012. 2013. 164 f. Tese (Doutorado em Economia) - Universidade Federal de Minas Gerais, Belo Horizonte, 2013.

PERROUX, F. A economia do século XX. Porto: Herder, 1967.

PERTILE, N. A formação do espaço agroindustrial em Santa Catarina: o processo de produção de carnes no oeste catarinense. 2008. 322 f. Tese (Doutorado em Geografia)- Universidade Federal de Santa Catarina, Florianópolis, 2008.

QUEIROZ, M.V. Messianismo e conflito social: a guerra sertaneja do Contestado 1912/1916. Rio de Janeiro: Civilização Brasileira, 1966.

RAFFESTIN, C. Por uma geografia do poder. São Paulo: Ática, 1993. 
SANTOS, J. L.; SCHMIDT, P.; FERNANDES, L. A. Contabilidade avançada: aspectos societários e tributários. São Paulo: Atlas, 2003. p. 284-308.

SCAPIN, A. Videira nos caminhos de sua história.Videira: Prefeitura Municipal, 1996.

SOUZA, N. J. Desenvolvimento regional. São Paulo: Atlas, 2005.

TASSARA, H. Perdigão: uma trajetória para o futuro. São Paulo: Empresa das Artes, 1996.

VALENTINI, D. J. Atividades da Brazil Railway Company no sul do Brasil: a instalação da Lumber e a guerra na região do contestado: 1906-1916. 2009. 301 f.Tese (Doutorado em História) - Pontifícia Universidade Católica do Rio Grande do Sul, Porto Alegre, 2009. 
Recebido em: 09/02/2018

Aceito em: 20/06/2018 